\title{
Air Guns: Would You Buy These "Toys” for Your Children?
}

\author{
Saniye Göknil Çalık' (D), Mustafa Çalık² (D), Hıdır Esme² (1)
}

Society and legislators perceive air guns (AGs) as toys or harmful items. Injuries in the thorax range from simple superficial ones to life-threatening ones. Although literature reports an alarming increase in the frequency and seriousness of the injuries caused by, the injuries rarely lead to death. Here, we presented a patient who was injured due to a potentially life-threatening AG. A 14-year-old boy was presented to our emergency department with chest injury after he had been shot by mistake by his 8-year-old brother with an air rifle from a distance of approximately $3 \mathrm{~m}$. Upon examination, a single entrance wound at the right third intercostal space without exit wound and subcutaneous emphysema were observed. Computed tomography revealed right hemopneumothorax, lacerations, and right lung contusions. The patient was discharged on postoperative day five without any complications. Legislators should implement laws to avoid AG injuries and even deaths. Necessary steps should be taken to strictly control the registration, sale, and use of Ags like the equivalent guns. There is one question that the readers should address. Would you buy these "toys" for your children? As a father, I would definitely not.

Keywords: Air gun, chest, injury

ORCID IDs of all authors: M.C.. 0000-0001-99635724; S.G.C.. 0000-0001-5545-3937; H.E. 00000002-6569-8193.

This study was presented as a oral presentation in the $3^{\text {rd }}$ Intercontinental Emergency Medicine Congress, 3rd International Critical Care and Emergency Medicine Congress, 19-22 May 2016, Antalya, Turkey.

${ }^{1}$ Vocational School of Health Services KTO Karatay University, Konya, Turkey.

${ }^{2}$ Department of Thoracic Surgery, Health Sciences University, Konya Training and Research Hospital, Konya, Turkey

\section{Address for Correspondence:}

Mustafa Çalık

E-mail: drmcalik@hotmail.com

Received: 01.08.2017

Accepted: 20.11.2017

C Copyright 2018 by Available online at istanbulmedicaljournal.org

\section{Introduction}

Trauma caused by a bullet is serious and has been discussed in detail in medical literature (1). Air guns (AGs) are a type of weapons that shoot slugs and bullets using compressed air. Historically, AGs are powerful weapons with a capacity to kill. In fact, current guns operate using the same principle. Gunpowder rapidly expands after firing and produces high pressure, because of which the bullet is propelled forward. AGs use air pistons, springs, or nitrogen/carbon dioxide tubes filled under pressure as power supply instead of gunpowder (2). Nearly all AGs are able to pass through the skin and even bone. Although these facts have been established for years, these "toys" are being sold without issuing a license under very low legal restrictions without controlling their use (3). Although restrictions regarding AGs are regulated today, they can still cause serious and lifethreatening injuries when used for injuring a suitable area and when fired from an appropriate distance. Here, we presented a patient that was injured because of a potentially life-threatening AG.

\section{Case Report}

A 14-year-old male had been shot by mistake by his 8-year-old brother with an air rifle (KRAL Magnum 45590, 0.177-caliber) from a distance of approximately $3 \mathrm{~m}$. He presented to the emergency department of our hospital with complaints of chest pain and shortness of breath. During consultation, he was moderately conscious and cooperatively oriented; his blood pressure was $115 / 85 \mathrm{~mm} \mathrm{Hg}$, pulse rate was 136 beats per minute, body temperature was $37.4^{\circ} \mathrm{C}$, and saturation was $92 \%$ without oxygen. Physical examination revealed a round-shaped entrance orifice sized of $0.4 \times 0.5 \mathrm{~cm}$ with a clot located laterally at a distance of $5 \mathrm{~cm}$ from the sternum in the third intercostal interval of the right hemithorax and no color change in its sharply circumscribed surrounding that could be easily discriminated from the surrounding tissues. No exit orifice could be found (Figure 1a, b). Subcutaneous emphysema was noted in the described area; the right hemithorax was reduced in respiration, and breathing sound was decreased in the lower zone of the right hemithorax. Thorax computed tomography, identified the following: air densities (subcutaneous emphysema) in the under-skin soft tissues of the right hemithorax frontal wall of the thorax, hyperdensed contusion with a diameter of approximately $5 \mathrm{~cm}$ showing a linear extension on the anterior-posterior plane in the apex of the right lung's upper part in the medial, hemopneumothorax with a diameter reaching approximately $13 \mathrm{~mm}$ at the thickest area in the right hemithorax, and a slug piece with a diameter of $9 \mathrm{~mm}$ leading to a metallic artifact under the skin in between muscle planes adjacent to the right second thoracic (T2) vertebra transverse 
process (Figure 2). Owing to hemopneumothorax, when the chest tube was closed, underwater drainage was applied to the patient from the right hemithorax fifth intercostal interval in operating room conditions. Air leak was observed after chest tube insertion
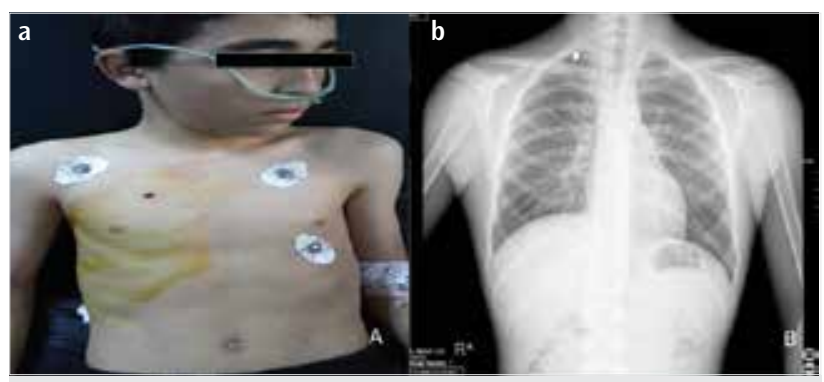

Figure 1. a,b. A single round-shaped entrance wound at the right third intercostal space (white arrow) of the patient (a); Anteroposterior views of the chest radiograph of the patient showing the pellet (white arrow) (b)

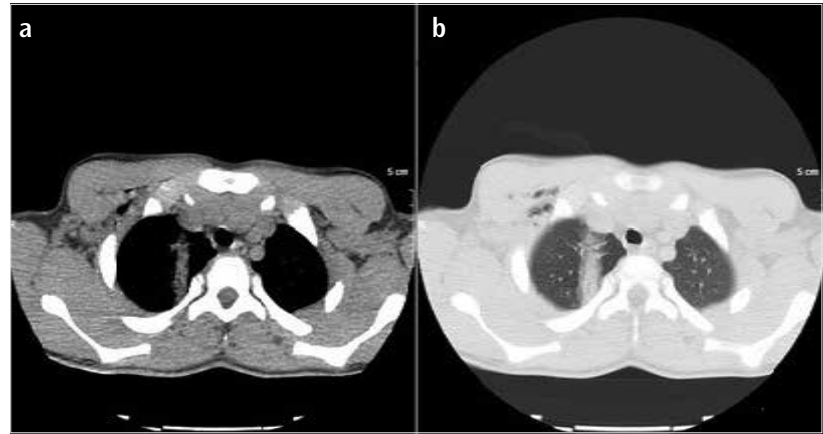

Figure 2. a, b. Axial views of the thorax computed tomography scan showing that the pellet literally crossed from the anterior to the posterior aspect of the chest

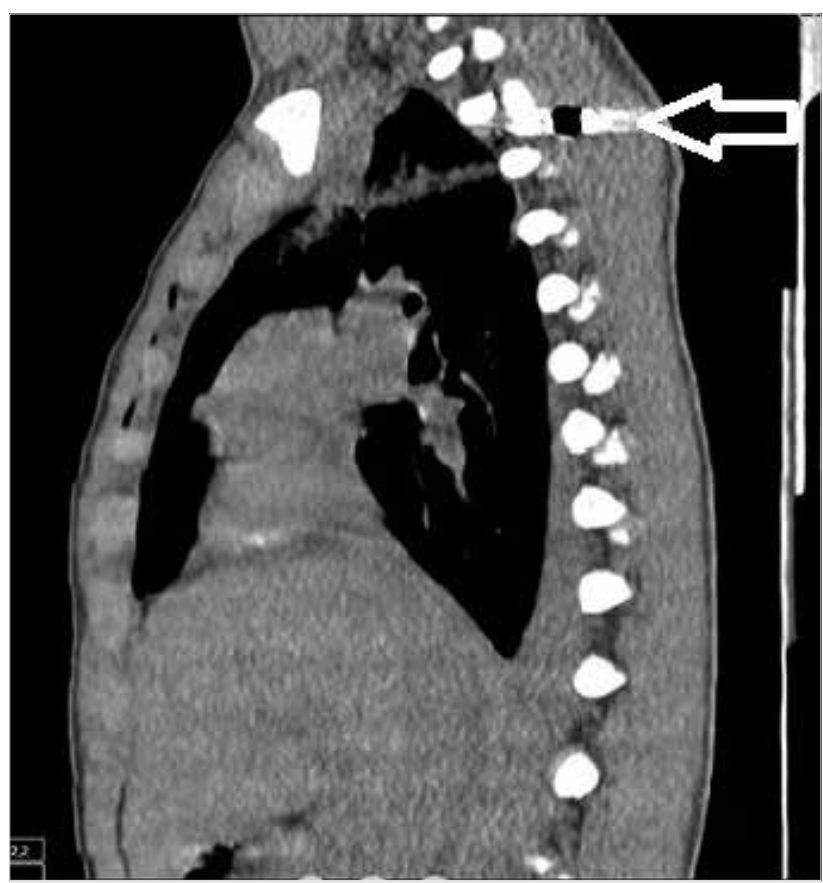

Figure 3. Sagittal view of the thorax computed tomography showing hyperdensed contusions extending from the anterior to the posterior in the right upper lobe and metallic artifact under the skin in between muscle planes adjacent to the right second thoracic vertebra transverse process (white arrow) and was stopped on the third day. A volume of 200 cc was drained on the first day, and the total drainage was 350 cc. Drainage was discontinued, and the patient was discharged on the fifth day of hospitalization. Written informed consent was obtained from the patient's legal guardian for the use of his medical records in research.

\section{Discussion}

AGs are perceived as toys or harmful items by the society and legislators. Their origin is ancient. At the beginning of the $20^{\text {th }}$ century, AGs were used for hunting purposes and as toys $(2,4)$. The identification, ownership, and purchasing criteria of AGs vary from country to country and even in between states within the same country (4-6). Any citizen aged more than 18 years can purchase AGs without any limitation. In our country, the export of only AGs with a muzzle velocity higher than $175 \mathrm{~m} / \mathrm{s}$ is prohibited. However, its manufacture, purchase, sale, and use in the areas determined by laws are free in our country. Recently, our legislators have prohibited the use of AGs in residential, meeting and hunting areas because of public constrains. Furthermore, including the purchase invoice and locating the single use tubes and slugs out of the gun were imposed as obligations (7). Although these restrictions offer hope, they are not sufficient.

In the literature, injuries caused by AGs are mostly seen in boys younger than 16 years who were shot by accident by their relatives. The injury is usually localized in the eye, head, and neck. In this respect, our case complied with the literature in terms of age and gender. Deaths due to AGs were rarely reported, and injuries to the airways and neurovascular structures in the head-neck area were mostly reported. Chest injuries were reported at $2 \%$ (5). The number of reported deaths was extremely low, and all of them were because of cardiac injury, except for one case, which was an attempted murder; the bullet entered through the eight intercostal space and stopped the left ventricular wall by tearing down the left lower lobe and its veins (2). In our case, the bullet entered through the right anterior third intercostal space, passed the upper lobe of the right lung, and stopped under the skin in between muscle planes adjacent to the right $\mathrm{T} 2$ transverse process (Figure 3). Although the injury led to hemopneumothorax, we believe that death did not occur because of the fact that the right upper lobe and important mediastinal vascular structures were not affected. The potential of AGs to cause injury does not only depend on muzzle velocity and the ammunition used, but also on the age of the victim, anatomy of the injury area, distance, and clothes worn by the victim (6).

Bullets with a velocity higher than $609.6 \mathrm{~m} / \mathrm{s}$ are called bullets with high energy, whereas the ones with a velocity lower than 457.2 $\mathrm{m} / \mathrm{s}$ are called bullets with low energy. Our case includes an injury caused by a bullet with low energy. It is different from injuries of bullets with low energy such as our case. The damages caused are laceration, penetration, crushing/contusion, and temporary cavity for a short period $(4,6,8)$. A hyperdensed contusion with a diameter of approximately $5 \mathrm{~cm}$ showing linear extension on the anterior-posterior plane in the right lung upper lobe apex medial was present in our patient, as identified in literature (Figure 3). The bullet passed the thorax with a kinetic energy of $32.67 \mathrm{~J}$ from end to end and stopped under the skin adjacent to the right $\mathrm{T} 2$ transverse process. It traveled $147.2 \mathrm{~mm}$ in the skin (9). 
Injuries in the thorax range from simple superficial ones to life-threatening injuries. Every year, one or two people die because of injuries caused by AGs in the United Kingdom, where there are supposedly 4 million AGs; four people die for the same reason in the United States $(1,10)$. It may escape attention owing to the small entrance orifice in crowded and busy emergency services such as the ones in our country. Despite the restricted power and low kinetic energy of AGs, they may lead to serious or life-threatening injuries in suitable injury area and distance. Each AG injury has to be accepted as an injury caused by a gun with low energy and should be treated accordingly. Surgical exploration and pellet removal are contradictive. Although emboli and migration cases have been reported in the literature, discussions show that leaving it in the body is less risky than its removal (4). In our case, surgery was not performed due to limited drainage and because the pellet was far from important neurovascular structures.

\section{Conclusion}

Although the frequency and seriousness of the injuries caused by AGs is increasingly alarming when considering the literature, they rarely lead to death. Majority of the reported cases are neurovascular injuries around the head-neck area, and more rarely cardiac injuries (4). Injuries caused by AGs should be treated like the injuries caused by guns with low energy. It should be always kept in mind that they may cause serious, and even fatal, injuries under suitable conditions. It is in the power of legislators rather than us as clinicians to avoid injuries and even deaths. Necessary steps should be taken to strictly control their registration, sale, and use like the equivalent firearms guns.

Informed Consent: Informed consent was obtained from patient who participated in this study.

Peer-review: Externally peer-reviewed.

Author Contributions: Concept - S.G.C., M.C.., H.E.; Design - S.G.C.., M.Ç.; Supervision - S.G.C., M.C., H.E.; Resource - S.G.C., M.Ç., H.E.; Materials - S.G.Ç., M.Ç., H.E.; Data Collection and/or Processing - S.G.C.., M.Ç., H.E.; Analysis and/or Interpretation - S.G.C.., M.C.; Literature Search - S.G.C.., M.C..; Writing
- S.G.C., M.Ç.; Critical Reviews - S.G.C.., M.C..

Conflict of Interest: Authors have no conflicts of interest to declare.

Financial Disclosure: The authors declared that this study has received no financial support.

\section{References}

1. Wightman G, Cochrane R, Gray RA, Linton M. A contribution to the discussion on the safety of air weapons. Sci Justice 2013; 53: 343-9. [CrossRef]

2. Bligh-Glover WZ. One-in-a-million shot: a homicidal thoracic air rifle wound, a case report, and a review of the literature. Am J Forensic Med Pathol 2012; 33: 98-101. [CrossRef]

3. Di Maio VJ. Homicidal death by air rifle. J Trauma 1975; 15: 1034-7. [CrossRef]

4. Abad S, McHenry ID, Carter LM, Mitchell DA. Carotid artery injury from an air gun pellet: a case report and review of the literature. Head Face Med 2009; 17; 5:3.

5. Veenstra M, Prasad J, Schaewe H, Donoghue L, Langenburg S. Non powder firearms cause significant pediatric injuries. J Trauma Acute Care Surg 2015; 78: 1138-42. [CrossRef]

6. Bakovic M, Petrovecki V, Strinovic D, Mayer D. Shot through the heartfire power and potential lethality of air weapons. J Forensic Sci 2014; 59: 1658-61. [CrossRef]

7. 2521 sayılı avda ve sporda kullanılan tüfekler, nişan tabancaları ve av bıçaklarının yapımı, alımı, satımı ve bulundurulmasına dair kanun Resmî Gazete No:2720822 Nisan 2009 http://www.resmigazete.gov.tr/ eskiler/2009/04/20090422-10.htm

8. Stankov A, Jakovski Z, Pavlovski G, Muric N, Dwork AJ, Cakar Z. Air gun injury with deadly aftermath-case report. Leg Med(Tokyo) 2013;15: 35-7. [CrossRef]

9. Hallikeri VR, Gouda HS, Kadagoudar SA. Country made scare gun vs. airgun-a comparative study of terminal ballistics using gelatine blocks. Forensic Sci Int 2012; 214: 148-51. [CrossRef]

10. Laraque D; American Academy of Pediatrics Committee on Injury, Violence, and Poison Prevention. Injury risk of non-powder guns. Pediatrics 2004; 114: 1357-61. [CrossRef]

Cite this article as: Çalık SG, Çalık M, Esme H. Air Guns: Would you Buy these "Toys" for your Children? İstanbul Med J 2018; 19: 180-2. 